\title{
ASO Author Reflections: Postoperative Complications are not Associated with Decreased Health-Related Quality of Life in Patients Following Esophagectomy for Esophageal or Gastroesophageal Junction Cancer
}

\author{
Egle Jezerskyte, $\mathrm{MD}^{1}$ (D), Mark I. van Berge Henegouwen, $\mathrm{MD}, \mathrm{PhD}^{1}$, Mirjam A. G. Sprangers, $\mathrm{MD}$, $\mathrm{PhD}^{2}$, and \\ Suzanne S. Gisbertz, MD, PhD ${ }^{1}$ \\ ${ }^{1}$ Department of Surgery, Cancer Center Amsterdam, Amsterdam UMC, University of Amsterdam, Amsterdam, The \\ Netherlands; ${ }^{2}$ Department of Medical Psychology, Amsterdam UMC, University of Amsterdam, Amsterdam, The \\ Netherlands
}

\section{PAST}

Esophagectomy has major effects on health-related quality of life (HRQoL), and postoperative complications might contribute to decreased HRQoL. Overall, an impaired short- and long-term HRQoL is reported by patients with postoperative complications compared with patients without postoperative complications following an esophagectomy. ${ }^{1-4}$ However, previous studies either did not include a baseline measurement or information on (neo)adjuvant treatment, were performed before the implementation of minimally invasive surgery, or the study was conducted in a single center with a limited number of patients. In the present study, ${ }^{5}$ we dealt with these objections.

\section{PRESENT}

In the current population-based prospective cohort study, ${ }^{5}$ we hypothesized that postoperative complications negatively influence short- and long-term HRQoL. This study targeted 486 patients with esophageal or gastroesophageal junction cancer who were treated with esophagectomy with, among others, minimally invasive

(C) The Author(s) 2021

First Received: 17 May 2021

Accepted: 17 May 2021;

Published Online: 4 June 2021

S. S. Gisbertz, MD, PhD

e-mail: s.s.gisbertz@amsterdamumc.nl surgery and neoadjuvant/perioperative therapy. We found that in general, postoperative complications were not associated with decreased short- and long-term HRQoL in patients up to 24 months post-esophagectomy. We also found a significant decline in short-term HRQoL in patients with or without complications in various HRQoL domains, which restored to baseline level at 12 months of follow-up. No significant difference was found in HRQoL between patients with and without anastomotic leakage. Patients with grade 2-3 anastomotic leakage reported significantly more 'choking when swallowing' at 6,9 , and 24 months than patients with grade 1 or no anastomotic leakage.

\section{FUTURE}

Contrary to our expectations, these results suggest that the occurrence of postoperative complications did not influence short- and long-term HRQoL in patients with esophageal or gastroesophageal junction cancer after surgery. We encourage clinicians to inform patients about the significant decline in short-term HRQoL that restores to baseline level at 12 months of follow-up. The temporary decrease in HRQoL was probably related to the nature of the esophagectomy and reconstruction itself. These findings could stimulate future studies to focus on how to minimize the temporary functional complaints caused by esophageal cancer surgery with gastric tube reconstruction.

DISCLOSURE E. Jezerskyte, M.A.G. Sprangers and S.S. Gisbertz have no conflicts of interest to declare.M.I. van Berge Henegouwen has a consultant role with Alesi Surgical, Mylan, Johnson and Johnson and Medtronic. Research funding from Olympus and Stryker. 
OPEN ACCESS This article is licensed under a Creative Commons Attribution 4.0 International License, which permits use, sharing, adaptation, distribution and reproduction in any medium or format, as long as you give appropriate credit to the original author(s) and the source, provide a link to the Creative Commons licence, and indicate if changes were made. The images or other third party material in this article are included in the article's Creative Commons licence, unless indicated otherwise in a credit line to the material. If material is not included in the article's Creative Commons licence and your intended use is not permitted by statutory regulation or exceeds the permitted use, you will need to obtain permission directly from the copyright holder. To view a copy of this licence, visit http://creativecommons. org/licenses/by/4.0/.

\section{REFERENCES}

1. Kauppila JH, Johar A, Lagergren P. Postoperative complications and health-related quality of life 10 years after Esophageal Cancer Surgery. Ann Surg. 2020;271(2):311-6.

2. Derogar M, Orsini N, Sadr-Azodi O, Lagergren P. Influence of major postoperative complications on health-related quality of life among long-term survivors of esophageal cancer surgery. J Clin Oncol. 2012;30(14):1615-9.

3. Scarpa M, Saadeh LM, Fasolo A, Alfieri R, et al. Health-related quality of life in patients with oesophageal cancer: analysis at different steps of the treatment pathway. J Gastrointest Surg. 2013;17(3):421-33.

4. van der Schaaf M, Lagergren J, Lagergren P. Persisting symptoms after intrathoracic anastomotic leak following oesophagectomy for cancer. Br J Surg. 2012;99(1):95-9.

5. Jezerskyte E, van Berge Henegouwen MI, van Laarhoven HWM, van Kleef JJ, Eshuis WJ, Heisterkamp J, Hartgrink HH, Rosman C, van Hillegersberg R, Hulshof MCCM, Sprangers MAG, Gisbertz SS; Dutch UpperGI Cancer Group. Postoperative Complications and Long-Term Quality of Life After Multimodality Treatment for Esophageal Cancer: An Analysis of the Prospective Observational Cohort Study of Esophageal-Gastric Cancer Patients (POCOP). Ann Surg Oncol. 2021. https://doi.org/10.1245/s10434-021-101445 .

Publisher's Note Springer Nature remains neutral with regard to jurisdictional claims in published maps and institutional affiliations. 